\title{
Scour of soil with dynamics interactions among soil-water induced by jet flow
}

\author{
T. Matsuda \\ Toyohashi University of Technology, Toyohashi, Japan \\ K. Maeda \& A. Yamaguchi \\ Nagoya Institute of Technology, Nagoya, Japan
}

\begin{abstract}
The present study attempted to explicate the scouring mechanism due to overflow focusing on the tractive force and the pore water pressure in the ground by using several geomaterials. For example; In the case of sandy soil, the scour profile has same profile as proposed by Yeh et al (2006), and the excess pore water pressure was generated. Especially, the excess pore water pressure was severely increased and it increased with the depth of sedimentation ground increased due to jet flow. As a result, the effective overburden pressure became zero, and a fluidization/liquefaction-like phenomenon occurred. Moreover, we investigated the mechanics of generate the excess pore water pressure in the ground induced by jet flow by using SPH method. As a simulation results, we found that the generating excess pore water pressure in the porous rigid ground was lower than the $1 \mathrm{~g}$-field model test.
\end{abstract}

\section{INTRODUCTION}

Scour phenomenon in the ground induced by water flow will cause the destabilization of the structures. For example, Disaster of the breakwater with scour due to tsunami overflow was occurred at Hachinoheport in East Japan Great Earthquake, 2011, Japan. The score phenomenon induced by overflow has not yet been discussed. In a past studies on the scouring, many researcher thought the application of a tractive force about prediction of topographical changes due to water flow. Tractive force evaluations, the scouring phenomenon is evaluated from a microscopic viewpoint, which takes into consideration the equilibrium condition between the shear force generated by the fluid force passing through the ground surface layer and the effective weight of soil particles in the outermost layer of the ground. As a recent study has pointed out, fluid force does not only affect the ground surface layer but also causes stress changes in the ground (e.g., Imase et al., 2012). Therefore, it is important to focus on mesoscopic and macroscopic perspectives in addition to the microscopic.

In this study, the scour mechanism induced by relatively fast flow (jet flow) was investigated by using the 1g-field model test and numerical simulation of particle based method. The present study attempted to explicate the scouring mechanism due to overflow focusing on the tractive force and the pore water pressure in the sediment ground by using several geo-materials that is different permeability. Moreover, this study is investigated the mechanics of gen- erate the excess pore water pressure in the ground induced by jet flow by using SPH method.

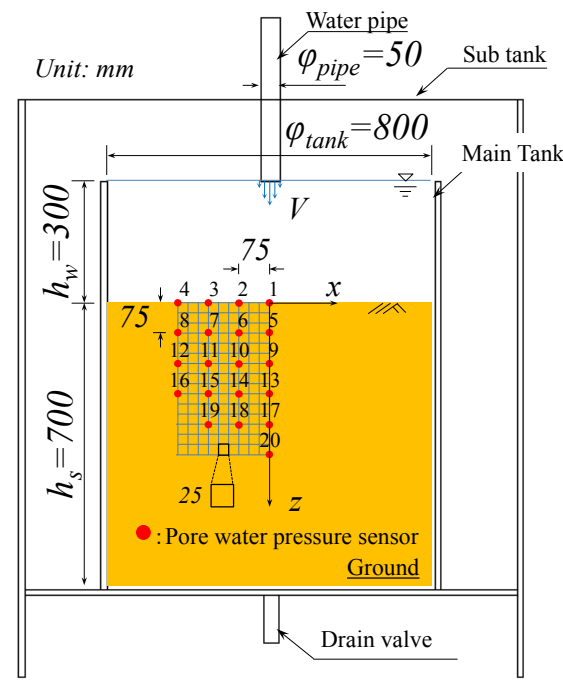

Figure 1. Schematic diagram of experimental device.

\section{OUTLINE OF EXPERIMENT}

\subsection{Experimental device and measurement tools}

In this study, was used the device that showed in Figure 1. The shape of device is half cylinder. The main tank was $0.7 \mathrm{~m}$ in diameter and $1.0 \mathrm{~m}$ in height.

In order to the external force, jet flow was generated by pipe that is set in the upper of the main tank using a submersible pump $(0.12 \mathrm{~m} 3 / \mathrm{min})$, taking into 
consideration Froude's similarity law. The pipe diameter is $0.05 \mathrm{~m}$ and the distance between the pipe and experimental ground surface was $0.3 \mathrm{~m}$. During the experiments, the pore water pressure in the ground was measured using pore water pressure sensors. The resolution of pore water pressure sensor is $5 \mathrm{~Pa}$. The measurement point of pore water pressure was shows by circle point in Figure 1. The experiments were recorded by using a high-speed camera (200-400 fps) and a video camera (29.97 fps) to observe scouring and corrosion.

\subsection{Experimental condition}

Table 1 shows the experimental cases and physical parameters of goematerial. In this experiment, two kinds of geomaterial were used. One of the geomaterials is Toyoura sand which is sandy soil. On the other hands, was used gravel. Each soil was settled in device, in $0.7 \mathrm{~m}$ height. In order to examine the effect of the scouring by the density, Toyoura sand had changed density. External force with pump of input velocity was generated about $2.06 \mathrm{~m} / \mathrm{s}$.

\section{EXPERIMENTAL RESULTS}

\subsection{Profile of scouring shape}

Figure 2 shows time histories of the scouring due to jet flow; (a) Toyoura sand, (b) Gravel. The scouring of gravel was not occurred. Therefore, this paper discuss on the scouring of the Toyoura sand in detail. Rapid scouring to vertical direction was generated at $x=0$ to $x=50 \mathrm{~mm}$ until $t=10 \mathrm{~s}$. After $t=20 \mathrm{~s}$, the maximum scouring depth converged, and horizontal scouring at a shallow from $\mathrm{z}=150 \mathrm{~mm}$ was generated.

The final scouring profile in this experiment was compared the result that was proposed by Yeh et al. (2009). Yeh et al. were presented the equation of scour profile as following:

$$
\begin{aligned}
& \varepsilon^{\prime}=-1.2 \exp \left[-0.5\left(\frac{r^{\prime}}{0.528}\right)^{2}\right]+0.4\left(\text { for }-1 \leq r^{\prime} \leq 1\right) \\
& \varepsilon^{\prime}=0.88 \exp \left[-0.5\left(\frac{r^{\prime}}{0.580}\right)^{2}\right](\text { other })
\end{aligned}
$$

where

$$
\begin{aligned}
& \varepsilon^{\prime}=\frac{\varepsilon}{\varepsilon_{\max }+\Delta} \\
& r^{\prime}=\frac{r}{r_{2}}
\end{aligned}
$$

there $r, r 2, \varepsilon, \varepsilon_{\max }$ and $\Delta$ are the radial direction, the radius of the scour hole at the ridge, the scour bed elevation, the maximum scour bed elevation and the ridge height, respectively.

Figure 3 were shown the scouring profile that compared the result of present experiment and the result by Yeh et al. As a result, the experimental result was shown almost the same scouring shape with the results of Yeh et al. However, at the center $\left(r^{\prime}=\right.$ $0.0)$ and $r^{\prime}=1.0$, it was underestimated the results of this experiment.

Table 1. Experimental cases and physical parameters of goematerial.

\begin{tabular}{c|c|c}
\hline Experiment case & Case1 & Case2 \\
\hline Inflow velocity: $\mathrm{m} / \mathrm{s}$ & \multicolumn{2}{|c}{2.06} \\
\hline Initial ground height: $\mathrm{m}$ & \multicolumn{2}{|c}{0.7} \\
\hline Geomaterial & Toyoura sand & Gravel \\
\hline $\begin{array}{c}\text { Midial diameter of ge- } \\
\text { omaterial: } D_{50} \mathrm{~mm}\end{array}$ & 0.17 & 25 \\
\hline $\begin{array}{c}\text { Permeability coeffi- } \\
\text { cient: } k \mathrm{~m} / \mathrm{s}\end{array}$ & $2.210 \times 10^{-4}$ & $8.349 \times 10^{0}$ \\
\hline
\end{tabular}

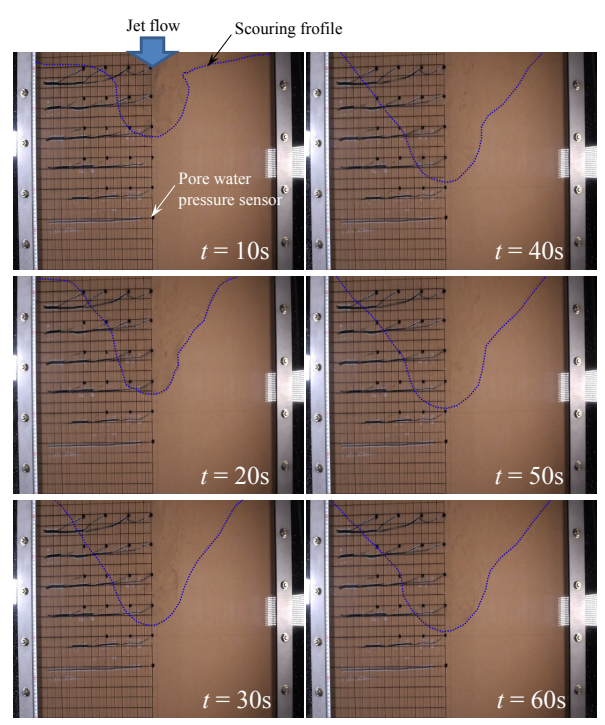

(a)

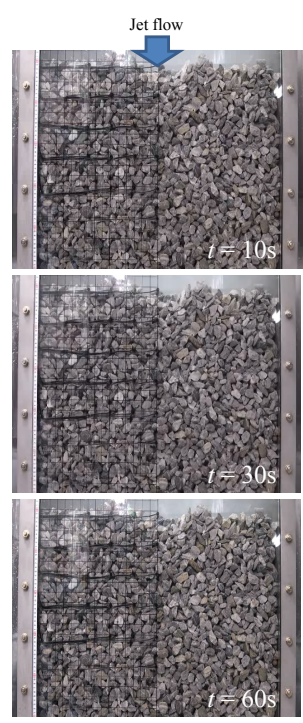

(b)
Figure 2. Time histories of scouring phenomenon; (a), Toyoura sand and (b), Gravel

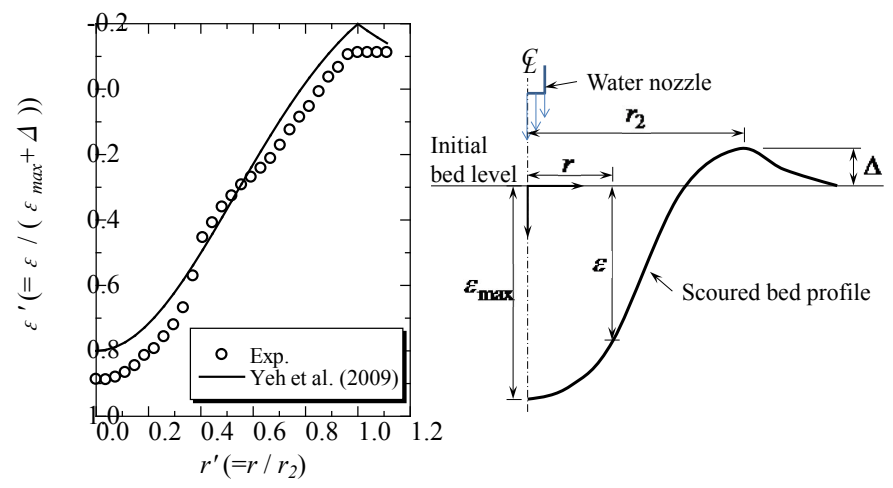

Figure 3. Scouring profile compared present experiment and result of Yeh et al. 


\subsection{Change in pore water pressure}

In this section, the change in pore water pressure in the soil due to jet flow was examined. Regarding validation for observed pressure, it was compared by using the formula of dynamic pressure proposed by Ishikawa (1982):

$P_{d}=\rho g \cdot \alpha \frac{v_{0}^{2}}{2 g}$

where

$$
\begin{aligned}
& \alpha=\frac{10.42}{2 x^{\prime}} \\
& x^{\prime}=\frac{h_{0}}{d_{0}}
\end{aligned}
$$

where $\rho, g$ and $v_{0}$ are density of water, the gravitational acceleration and initial velocity, respectively. Shown in Figure 1 are other parameters. Figure $X$ shows the time histories of excess pore water pressure in $\mathrm{CH} 9$. Moreover, it was added the theoretical value that is calculated by formula (1). As a calculation result, it was confirmed that the experimental values and the measured value is the same value $\left(P_{d} \doteqdot 1200 \mathrm{~Pa}\right)$.

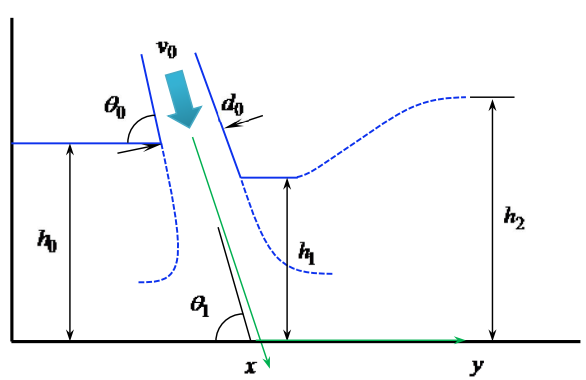

Figure 4. Schematic diagram of parameters that calculation of dynamic pressure due to overflow by using formula (1).

Figure 5 and Figure 6 shown the time histories of excess pore water pressure in the ground. Figure 5 shows result used Toyoura sand and Figure 6 shows result used Gravel. The excess pore water pressure is increasing the same volume about $250 \mathrm{~Pa}$ at all sensor in gravel. On the other hands, the excess pore water pressure was generated with the progress of the scouring when Toyoura sand was used. The case of Toyoura sand, the excess pore water pressure was increased about $500 \mathrm{~Pa}$ to $1,000 \mathrm{~Pa}$. It was not dissipated and has accumulated.

\subsection{Excess pore water pressure ratio}

Regarding the experiment case of Toyoura sand, the change in stress state induced by jet flow in ground was calculated that 1 dimensional vertical direction. The formulas of total stress and effective stress that are taking into account the progress of the scouring are shown as following: $\sigma=\gamma_{w}\left(h_{w}+\varepsilon\right)+\gamma_{s a t}\left(h_{s}-\varepsilon\right)$

$\sigma^{\prime}=\sigma-u$

where $\gamma_{w}, \gamma_{s a t}, h_{w}, \varepsilon$ and $h_{s}$ are unit weight of water, unit weight of saturated soil, water depth, scouring depth and initial covering thickness of soil, respectively.

Figure 7 shows the time histories of total stress, effective stress and pore water pressure. The calculation result in Figure 7 was used the excess pore water pressure at $\mathrm{CH} 9$ in present experiment.

The total stress and effective stress was decreased within the progress of the scouring. On the other hands, the excess pore water pressure was increased by jet flow and continued.

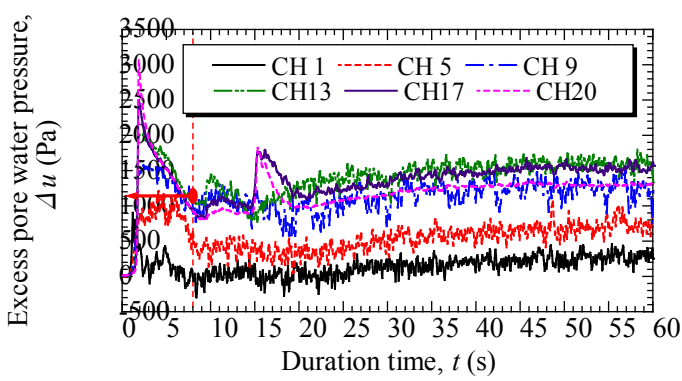

(a)

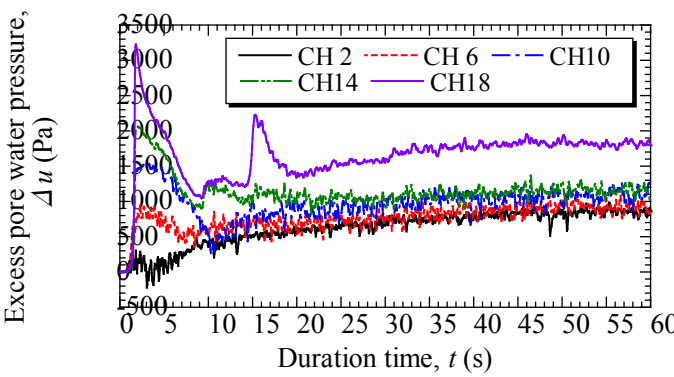

(b)

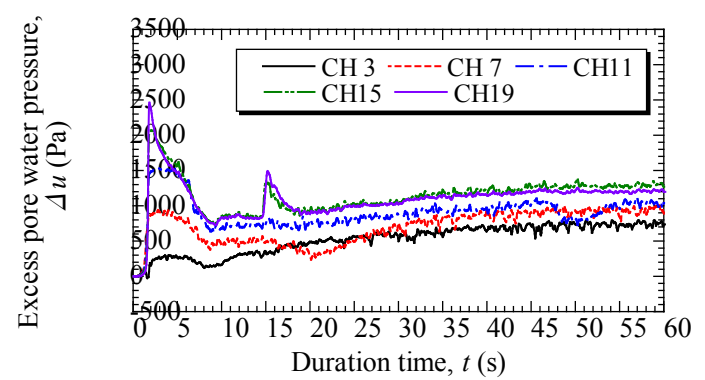

(c)

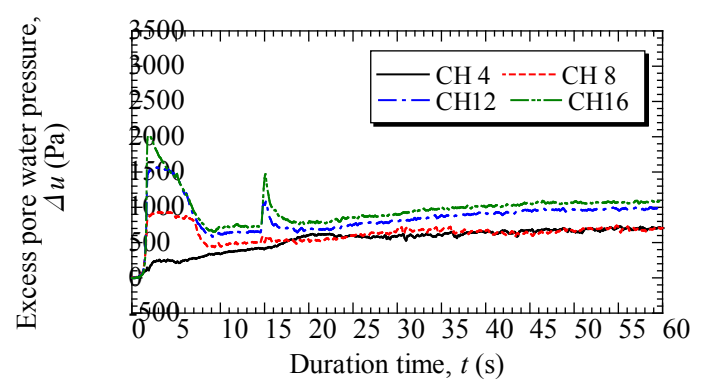

Figure 5. Time history of excess pore water pressure in the sandy ground due to jet flow; Toyoura sand. 


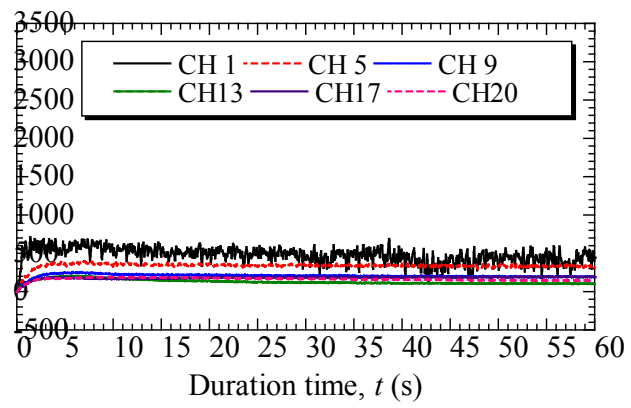

(a)

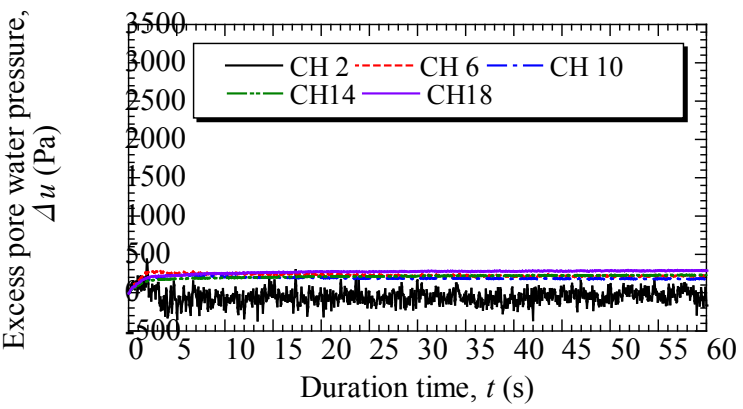

(b)

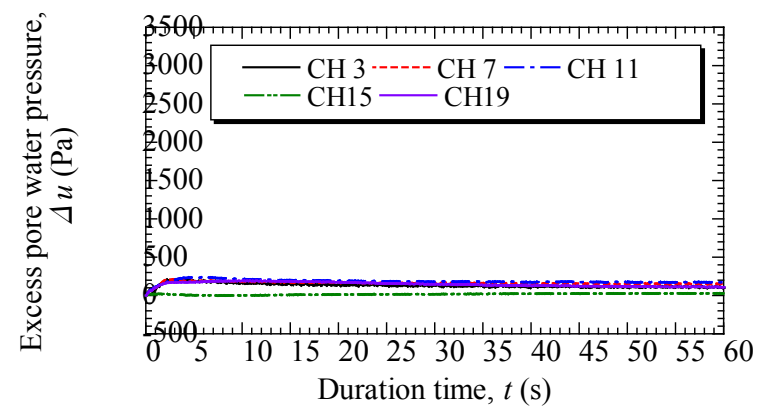

(c)

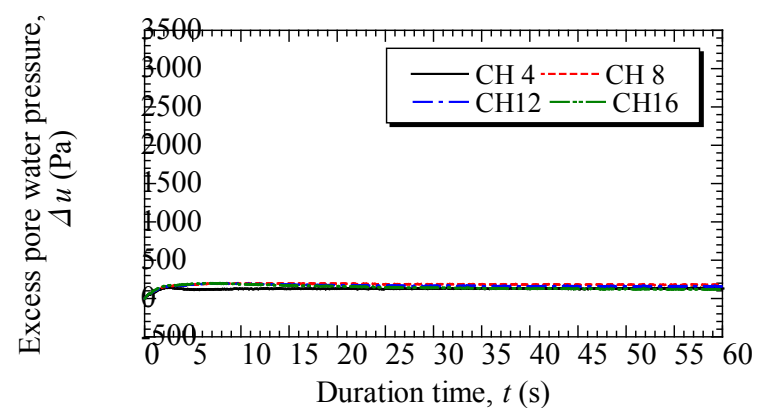

(d)

Figure 6. Time history of excess pore water pressure in the gravel ground due to jet flow; Gravel.
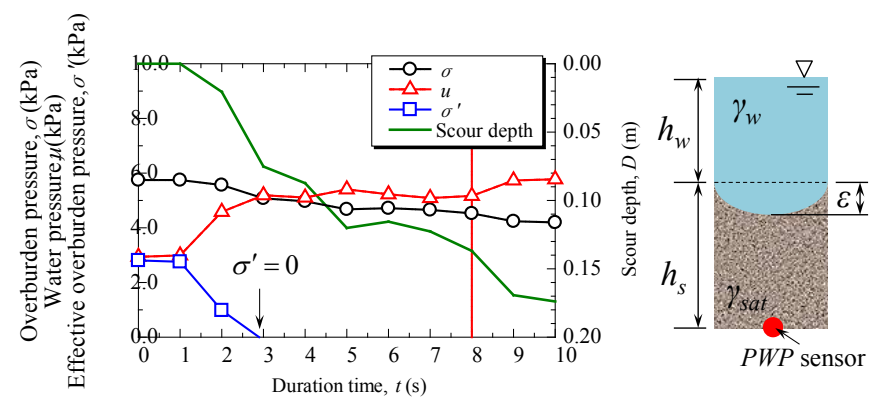

Figure 7. Time histories of total stress, water pressure and effective stress in the sandy ground due to jet flow.
As a result, the effective stress became zero and the stress state at $\mathrm{CH} 9$ area in the ground became liquefaction-like at $t=3 \mathrm{~s}$.

\section{NUMERICAL SIMULATION}

\subsection{Outline of SPH method}

The SPH method was developed from the field of astrophysics, and it uses a particle element (a radius of $h$ ), that moves and possesses a physical quantity, as a grid based on Lagrange's theorem (Lucy, 1977; Gingold and Monaghan, 1977). The physical quantity $f(\mathbf{x})$ of a marked particle element at the center $\mathrm{x}$ (position vector) is calculated by interpolating the physical quantity $f(\mathbf{x})$ of a particle element $\mathbf{x}$ within the area of influence using the smoothed function $W$ as follows:

$$
\langle f(\mathbf{x})\rangle=\int f\left(\mathbf{x}^{\prime}\right) W\left(\mathbf{x}-\mathbf{x}^{\prime}, h\right) d \mathbf{x}^{\prime}
$$

when discretization of a finite number (the total number of $N$ ) of particle elements is considered, Eq. (10) can be approximated as follows:

$$
f_{i}=\left\langle f_{i}\right\rangle=\sum_{j=1}^{N} m_{j} \frac{f_{j}}{\rho_{j}} W_{i j}\left(\mathbf{x}_{\mathrm{i}}-\mathbf{x}_{j}, h\right)
$$

where the position vector, mass, and density of particle element $i$ to be evaluated are expressed as $x_{i}, m_{i}$, and $\rho_{i}$, respectively, and the adjacent particle element is expressed as $j$. Since the integrated value of $\mathrm{W}$ in the region with a $2 h$ radius was 1 , the threedimensional spline function was used (Gingold and Monaghan, 1977).

\subsection{Coupling of soil and fluid phases}

Soil-fluid coupling is expressed in the SPH method by separately calculating a solid phase consisting of soil and a fluid phase for each layer, and the obtained results are overlapped. This allows soil-water coupled analysis to be performed (Maeda and Sakai, 2004). When overlapping, Darcy's law is assumed to apply and a body force that involves the porosity $n$ and water penetration coefficient $k$ acts between the soil and water. The body force is considered to arise due to the frictional force that is proportionally generated from the difference in velocity between these two phases, and it is defined based on Biot's theory (1941).

\subsection{Condition of Numerical simulation}

Figure 8 shows an initial condition of calculation. The geometry condition of calculation is same to this presented experiment. Jet flow has setting by inflow boundary condition. The water permeability coefficients of gravel and Toyoura sand were set as 
$1.0 \times 10^{-2} \mathrm{~m} / \mathrm{s}$ and $1.0 \times 10^{-5} \mathrm{~m} / \mathrm{s}$, respectively. In order to examine to the change in water pressure in ground due to jet flow, soil element has setting rigid-porous model $\left(\boldsymbol{V}^{s} \equiv \boldsymbol{0}\right)$.

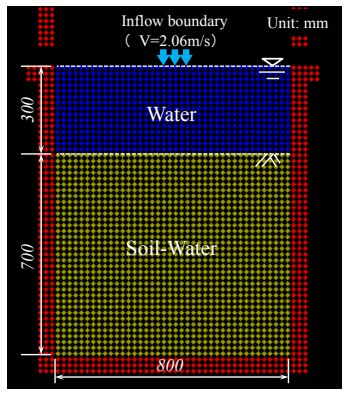

Figure 8 . Schematic diagram of analysis domain
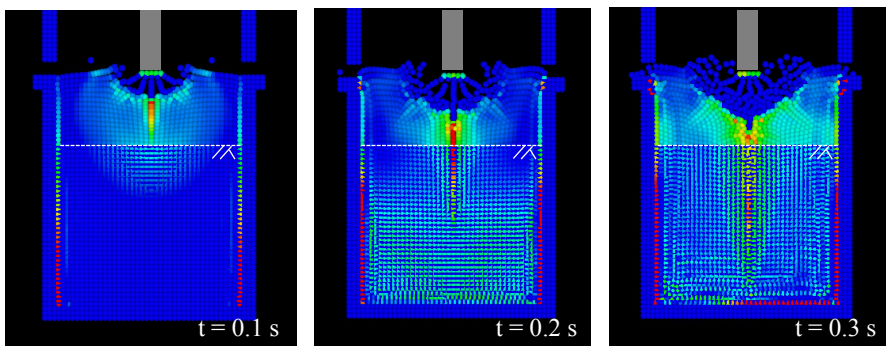

(a) Gravel: $k=1.0 \times 10^{-2} \mathrm{~m} / \mathrm{s}$
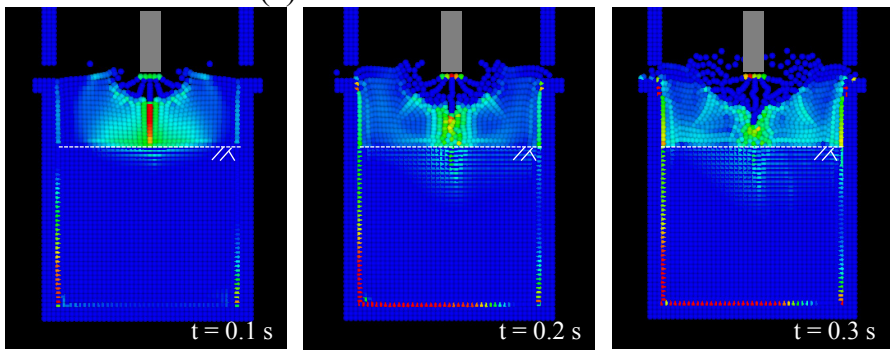

(b) Sandy soil: $k=1.0 \times 10^{-5} \mathrm{~m} / \mathrm{s}$

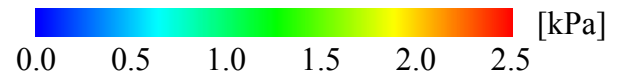

Figure 9. Change in the excess pore water pressure; (a), Gravel; (b), Sandy soil

\subsection{Numerical simulation results}

Figure 9 shows incremental water pressure contour maps. The case of gravel increased pressure throughout an analysis domain. On the other hands, the case of sandy soil increased pressure about 400$600 \mathrm{~Pa}$ at the region of shallower than the middle layer. As a result, the cause that measured of higher water pressure in this experiment using Toyoura sand is considered to effect of deformation of soil.

\section{CONCLUSION}

The present study attempted to explicate the scouring mechanism due to jet flow. The scouring profile was different by each geo-material. The ef-fect of scouring rate was influenced by tractive force. On the other hands, the excess pore water pressure was generated in sandy soil by jet flow. The case of Toyoura sand, the effective stress became zero be- cause increasing excess pore water pressure induced by jet flow and decreasing the effective stress by scouring, and a fluidization/liquefaction-like phenomenon occurred. A simulation results by using $\mathrm{SPH}$, the generating excess pore water pressure in the porous rigid ground was lower than the $1 \mathrm{~g}$-field model test. Therefore, we guess that generation of the larger excess pore water pressure induced by the jet flow to be due to the deformation of the ground. In future, we necessary to clarify to increasing excess pore water pressure by shear deformation of ground induced by jet flow.

\section{ACKNOWLEGMENTS}

The authors are grateful to the Japan Society for the Promotion of Science for its financial support with Grants-in-Aid for Scientific Research (B)23360203, Grant-in-Aid for JSPS Fellows 24-9200 and Grantin-Aid for Research Activity Start-up 26889035.

\section{REFERENCES}

Biot, M. A. 1941. General Theory of Three-dimensional Consolidation, Journal of Applied Physics, Vol. 12, pp. 152-164.

Gingold, R. A. and Monaghan, J. J. 1977. Smoothed Particle Hydrodynamics: Theory and Application to Non-spherical Stars, Monthly Notices of the Royal Astronomical Society, 181, pp. 375-389.

Imase, T., Maeda, K., Miyake, M., Tsurugasaki, K., Sawada, Y. and Sumida, H. 2012. Experimental Study on the Scouring Mechanism due to Open-Channel Flow and Overflow Focusing on Change in Pore Pressure, Journal of JSCE, Ser, B2(Coastal Engineering), 68(2), pp.I_836-I_840 (in Japanese).

Ishikawa T. 1982. Dynamic pressure in a energy dissipating basin of an arch dam. Journal of JSCE. No.327, pp. 99-105 (in Japanese).

Lucy, L. B. 1977. A Numerical Approach to the Testing of the Fission Hypothesis, Astronomical Journal, 82, pp. 1013-1024

Maeda, K. and Sakai, M. 2004. Development of Seepage Failure Analysis Procedure of Granular Ground with Smoothed Particle Hydrodynamics (SPH) Method, Journal of Applied Mechanics JSCE, Vol. 7, pp. 775-786 (in Japanese).

Yeh, P. -H., Chang K. -A., Henriksen J., Edge B., Chang P., Silver A. and Vargas A. 2009. Harge-scale laboratory experiment on erosion of sand beds by moving circular vertical jets, Ocean Eng., 36, pp. 248-255. 